\title{
Neuromuscular scoliosis complication rates from 2004 to 2015: a report from the Scoliosis Research Society Morbidity and Mortality database
}

\author{
Daniel Cognetti, ${ }^{1}$ Heather M. Keeny, PA-C, ${ }^{1}$ Amer F. Samdani, MD, ${ }^{1}$ Joshua M. Pahys, MD, ${ }^{1}$ \\ Darrell S. Hanson, MD, ${ }^{2}$ Kathy Blanke, RN, ${ }^{3}$ and Steven W. Hwang, MD ${ }^{1}$ \\ 1Shriners Hospitals for Children-Philadelphia, Pennsylvania; ${ }^{2 B}$ Baylor College of Medicine, Houston, Texas; and ${ }^{3}$ Scoliosis \\ Research Society, Milwaukee, Wisconsin
}

\begin{abstract}
OBJECTIVE Postoperative complications are one of the most significant concerns in surgeries of the spine, especially in higher-risk cases such as neuromuscular scoliosis. Neuromuscular scoliosis is a classification of multiple diseases affecting the neuromotor system or musculature of patients leading to severe degrees of spinal deformation, disability, and comorbidity, all likely contributing to higher rates of postoperative complications. The objective of this study was to evaluate deformity correction of patients with neuromuscular scoliosis over a 12-year period (2004-2015) by looking at changes in postsurgical complications and management.
\end{abstract}

METHODS The authors queried the Scoliosis Research Society (SRS) Morbidity and Mortality (M\&M) database for neuromuscular scoliosis cases from 2004 to 2015. The SRS M\&M database is an international database with thousands of self-reported cases by fellowship-trained surgeons. The database has previously been validated, but reorganization in 2008 created less-robust data sets from 2008 to 2011. Consequently, the majority of analysis in this report was performed using cohorts that bookend the 12-year period (2004-2007 and 2012-2015). Of the 312 individual fields recorded per patient, demographic analysis was completed for age, sex, diagnosis, and preoperative curvature. Analysis of complications included infection, bleeding, mortality, respiratory, neurological deficit, and management practices.

RESULTS From 2004 to 2015, a total of 29,019 cases of neuromuscular scoliosis were reported with 1385 complications, equating to a $6.3 \%$ complication rate when excluding the less-robust data from 2008 to 2011 . This study shows a 3.5-fold decrease in overall complication rates from 2004 to 2015. A closer look at complications shows a significant decrease in wound infections (superficial and deep), respiratory complications, and implant-associated complications. The overall complication rate decreased by approximately 10\% from 2004-2007 to 2012-2015.

CONCLUSIONS This study demonstrates a substantial decrease in complication rates from 2004 to 2015 for patients with neuromuscular scoliosis undergoing spine surgery. Decreases in specific complications, such as surgical site infection, allow us to gauge our progress while observing how trends in management affect outcomes. Further study is needed to validate this report, but these results are encouraging, helping to reinforce efforts toward continual improvement in patient care.

https://thejns.org/doi/abs/10.3171/2017.7.FOCUS17384

KEY WORDS neuromuscular scoliosis; complications; infection; cerebral palsy; Scoliosis Research Society

$\mathrm{O}$ VER the last three decades, the number of spine surgeries performed for deformity has greatly increased. Spinal fusions and scoliosis surgeries have increased substantially, in part due to advances in technology and techniques at specialized surgical centers. ${ }^{4,5,19,26,27,38,40}$ Despite our progress in the surgical man- agement of spine pathology, complication rates remain high for certain subgroups of scoliosis., ${ }^{3,12,12,14,30,33-35}$ One subgroup of scoliosis, neuromuscular scoliosis, has been associated with complication rates of more than $35 \%$ in recent studies, consistently higher than those of idiopathic scoliosis. ${ }^{23,29,31}$ Neuromuscular scoliosis is an irregular spi-

ABBREVIATIONS DVT = deep venous thrombosis; IONM = intraoperative neuromonitoring; M\&M = Morbidity and Mortality; MRSA = methicillin-resistant Staphylococcus aureus; MSSA = methicillin-sensitive Staphylococcus aureus; NSQIP = National Surgical Quality Improvement Program; PE = pulmonary embolism; SRS = Scoliosis Research Society; SSI = surgical site infection; VTE = venous thromboembolism.

SUBMITTED June 2, 2017. ACCEPTED July 13, 2017.

INCLUDE WHEN CITING DOI: 10.3171/2017.7.FOCUS17384. 
nal curvature caused by disorders of the muscles, brain, and/or spine. Common conditions associated with neuromuscular scoliosis are cerebral palsy, myelodysplasia, and muscular dystrophy. Patients with these conditions and associated scoliosis present unique challenges to surgeons. Higher degrees of disability and comorbid conditions may contribute to the reported higher complication rates. However, despite these challenges, surgical correction of these scoliotic curvatures provides benefit to patients; therefore, it is paramount to focus on reducing complications to minimize adverse patient outcomes. In an era in which hospital reimbursement is increasingly tied to hospital length of stay and complications, it is important to analyze surgical outcomes in greater detail as well. 6,29,37,42

The Scoliosis Research Society (SRS) is a global society of professionals involved in treating scoliosis with the aim of optimizing surgical treatment of spinal deformity. The SRS established an international database of complications for its fellows to report case data for this specific purpose. The SRS Morbidity and Mortality (M\&M) database is now one of the largest registries in the world, with thousands of cases reported each year. It has been validated multiple times and is comparable to databases such as the National Surgical Quality Improvement Program (NSQIP). ${ }^{12,21,33,34}$ Previous research, such as that from MacEwen et al., ${ }^{20}$ has examined complications for adolescent idiopathic scoliosis over a decade, while more recent research from Smith et al. ${ }^{33,34}$ and Hamilton et al. ${ }^{12}$ has investigated all SRS data for shorter periods of time. Similarly, this report seeks to use the SRS M\&M database, but specifically for patients with neuromuscular scoliosis over a 12-year period, to take a closer look at trends in complications and management.

\section{Methods \\ Data Collection}

Using the SRS M\&M database, we performed a retrospective analysis of patients with neuromuscular scoliosis undergoing spine surgery from 2004 to 2015. Data for the SRS M\&M database are obtained from cases self-reported by fellowship-trained surgeons who are active, international, or candidate members of the SRS. Active membership in the SRS requires surgeons to complete a 5-year candidate membership period. Candidate members are required to submit all spine case data, including M\&M, during that period. Candidacy is not affected by complication rate or type. Active members are also encouraged to submit cases. Recently, compliance has been as high as $80 \%-90 \% .^{9}$ Material for the database is collected using online questionnaires. All information is subsequently deidentified. The Western IRB for Shriners Hospitals determined that this study was exempt from approval. The SRS has put in considerable effort to create a database that has utility for clinicians and researchers. With that mission in mind, they reformed their data collection in 2008. For this reason, the database was closed to submissions for most of 2008. Due to the reorganization, data from 2009 onward were categorized differently. Many areas of interest were not affected; however, others were added, eliminated, or altered. Aside from a shortened year in 2008, data from
2009 to 2011 may be less robust because of the database alterations. Therefore, in our analysis of trends, we used 2004-2007 and 2012-2015 as our main cohorts.

Although the specific categorization of variables differed by time period, the overall fields included were consistent. Metrics for 312 variables were recorded, including but not limited to age, sex, curve magnitude, diagnoses, levels instrumented, type of complication (infection, bleeding, medical, neurological injury, mortality), and reoperation. When specific complications were identified, more data fields were requested, such as type of infection, bacteria, duration of treatment, and course. However, follow-up was somewhat limited as entries were made annually and longer follow-up was not solicited.

\section{Results \\ Demographics}

A total of 29,019 cases of neuromuscular scoliosis surgery were recorded in the SRS M\&M database between 2004 and 2015. Of those cases, 1385 were associated with a complication. This equates to a $6.3 \%$ overall complication rate when excluding the less-robust data from 2008 to 2011. The mean age for each year's cases with complications ranged from 13.5 to 17.2 years (Table 1). Sex was recorded in the database starting in 2007. Sex distribution ranged from $35.3 \%$ to $55 \%$ female (Table 1). The top 3 neuromuscular scoliosis diagnoses recorded for patients with complications were cerebral palsy $(n=601)$, myelodysplasia $(\mathrm{n}=202)$, and muscular dystrophy $(\mathrm{n}=102)$. Other less commonly specified categories included spinal muscular atrophy, posttraumatic, tumor, Rett syndrome, and Friedreich's ataxia. An "other" category $(n=267)$ was for conditions not specified in the questionnaire.

When comparing patients with complications from 2004-2007 and 2012-2015, there was no significant difference in the percentage of total procedures that were fusions. However, there were significant increases in the percentage of total fusions that were posterior only ( $\mathrm{p}<$ $0.01)$ and lumbar interbody $(\mathrm{p}<0.01)$. Posterolateral approach $(\mathrm{p}<0.05)$ along with anterior-only approach $(\mathrm{p}<$ 0.05 ) showed significant decreases in use. In terms of other surgical techniques, the use of implants $(\mathrm{p}<0.05)$ and osteotomies $(\mathrm{p}<0.001)$ have become increasingly prevalent in complication cases. The percentage of revision procedures associated with complications was also quite high (10.3\% 14.2\%), but no data exist for revisions after 2008. Lastly, intraoperative neuromonitoring (IONM) was used in 55.8\% $\pm 5.6 \%$ of the complication cases over the entire period but showed no significant change in usage throughout.

Preoperative spine curvature was reported starting in 2007. Curvature was logged in intervals of $10^{\circ}$. Figure 1 highlights the severe degree of preoperative spinal deformity in patients with complications following neuromuscular scoliosis surgery. The mode of preoperative curvature for $2007-2015$ was $71^{\circ}-80^{\circ}$, with $65 \%$ of cases at or above $71^{\circ}$ of curvature (Fig. 1).

\section{Complications}

The overall complication rate decreased by approximately 10\% from 2004-2007 to 2012-2015. The drop 


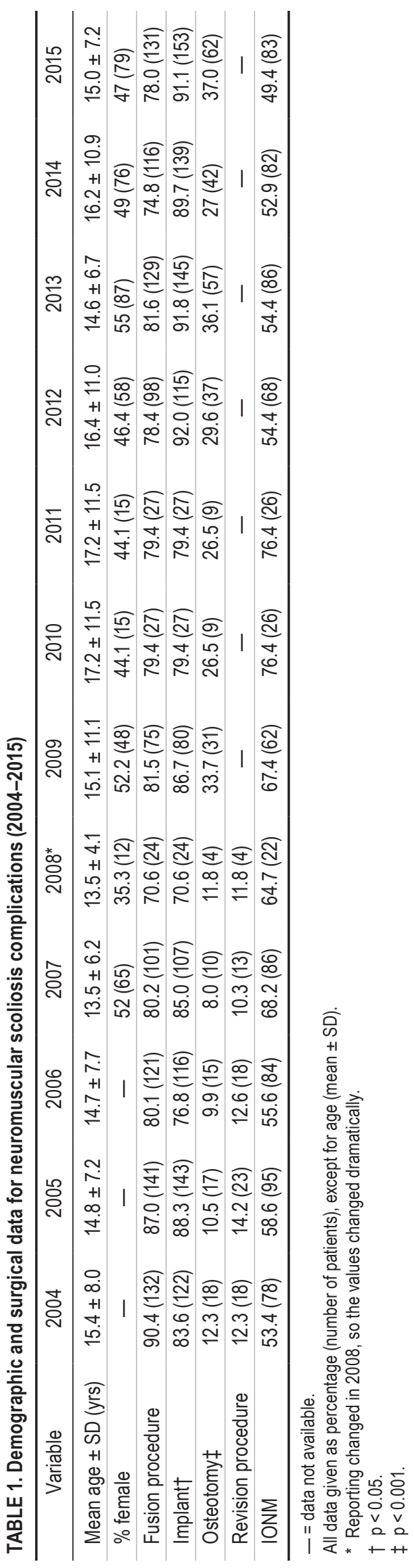

in complications came most notably from a decrease in wound infection rate by approximately $2 \%$ over the same time and from an overall decrease in other complications (Table 2). Accordingly, both superficial and deep wound infection incidence decreased significantly $(\mathrm{p}<0.001)$.

In 2012, the SRS added a microorganism specifier for infections. Microorganisms were classified as gram-negative or -positive and then further subclassified. There was no difference in the percentage of infections attributed to gram-positive or -negative from 2012 to 2015. Methicillinsensitive Staphylococcus aureus (MSSA) was the most commonly implicated organism, associated with $34.7 \%$ of the cultured wound infections. Two gram negatives, Escherichia coli and Pseudomonas, were the next highest at $17.7 \%$ and $12.5 \%$, respectively, with methicillin-resistant S. aureus (MRSA) at $10.5 \%$. The percentage of infection caused by each microorganism remained relatively stable from 2012 to 2015.

Over the same 4 years, the duration of oral and intravenous antibiotics was also recorded in the database. Intravenous antibiotics were used for 40-57 days, while oral antibiotics were used for 94-102 days. Cephalosporin was the most commonly used antibiotic, listed in $27.9 \% \pm$ $6.2 \%$ of cases, followed by vancomycin at $16.5 \% \pm 3.8 \%$ and fluoroquinolones at $15.6 \% \pm 5.5 \%$. Another infectioncontrol method recorded from 2012 on was wound infection washout. During the final 4 years, washouts were performed at least once in $84 \% \pm 3.0 \%$ of patients with infection. For those patients who had washouts, $27 \%$ had 3 or more washouts total. One final point of interest about infections is that even though they are decreasing overall, they are making up an increasingly larger proportion of total complications ( $p<0.0001$; Fig. 2).

Complications besides infection have a large role in morbidity and mortality as well. We looked more specifically at death, venous thromboembolism (VTE), other pulmonary complications, implant-related complications, neurological deficit, sepsis, epidural hematoma, and dural tears. However, there was only a significant decrease in other pulmonary complications (i.e., nonpulmonary embolism) and implant-related complications (Table 3).

\section{Discussion}

Previous research has shown that neuromuscular scoliosis complication rates are considerably higher than those reported in this study. ${ }^{23,29,31}$ The SRS M\&M database has produced somewhat lower results of complications in the past when compared with other databases such as the NSQIP, but the studies that demonstrated these differences still validated the SRS M\&M as a resource..$^{12,21 \text {, }}$ $33,34,39$ The differences in our results are possibly due to an underreporting of medical complications. Because the SRS M\&M database is a self-reported database, there is an inherent bias toward immediate surgical complications rather than other, possibly latent, medical complications. Furthermore, the annual reporting of complications limits follow-up of these patients and may inherently limit reporting of delayed complications. Nonetheless, a trend of significant decline in complications was consistently reported throughout the study. 


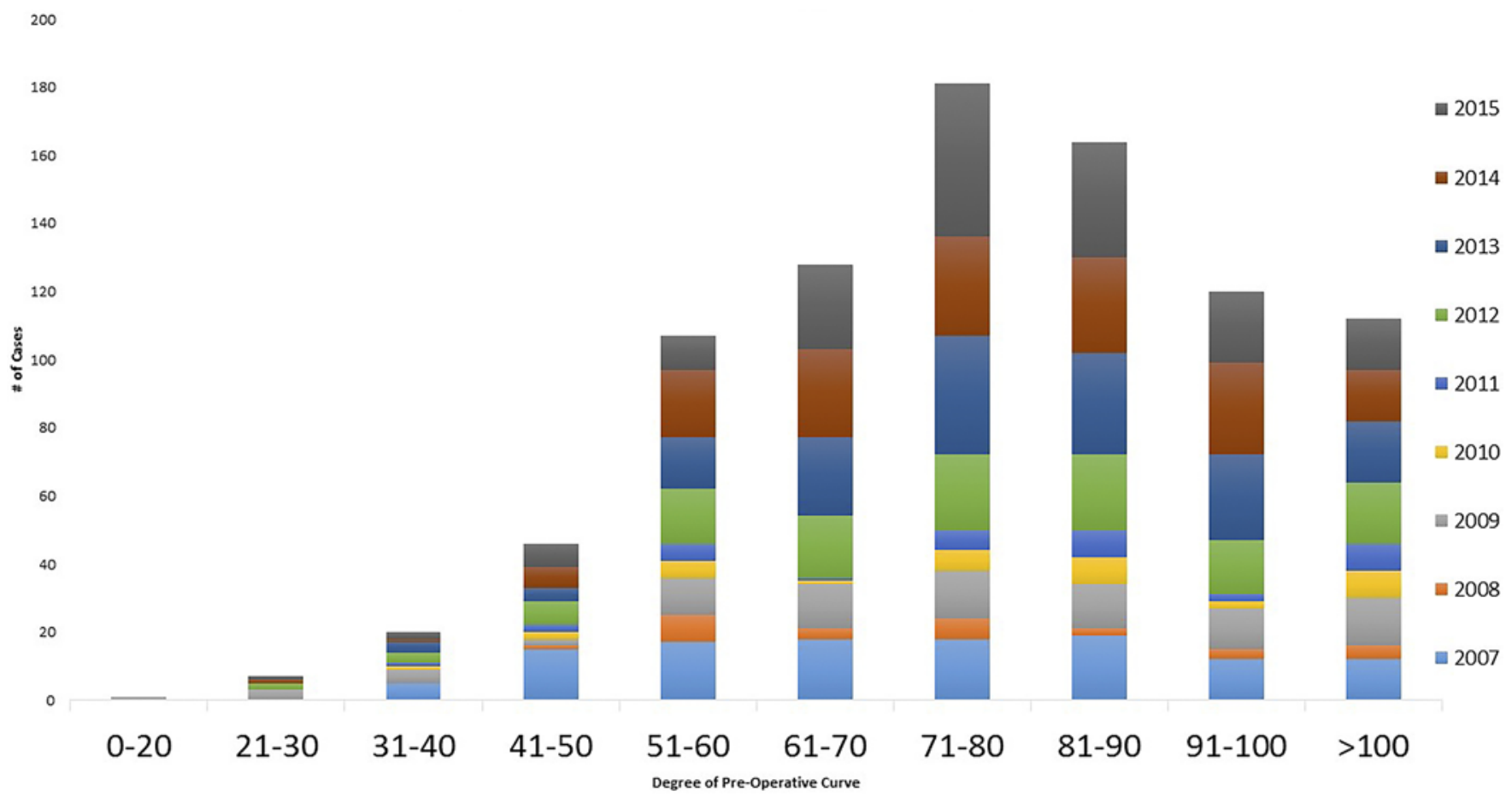

FIG. 1. Graph of the preoperative curve magnitude from 2007 to 2015.

In this study, we used records from the SRS M\&M database (2004-2015) to examine complication rates in patients with neuromuscular scoliosis following spine surgery. Our study shows a 3.5-fold decrease in overall complication rates, from $14.75 \% \pm 1.3 \%$ in $2004-2007$ to $4.08 \% \pm 0.4 \%$ in $2012-2015$. A closer look at complications shows a significant decrease in wound infections (superficial and deep), respiratory complications, and implant-associated complications.

Surgical site infection (SSI) in patients undergoing corrective surgery for neuromuscular scoliosis has been reported in 5\%-20\% of patients. ${ }^{18,34,35}$ We report an incidence of wound infection from 2004-2007 of 5.7\% \pm $0.3 \%$, similar to the $5.6 \%$ incidence rate of wound dehiscence and SSI during primary hospitalization reported by Rumalla et al. ${ }^{29}$ Our data for superficial $(1.8 \%-1.9 \%)$ and deep (3.5\%-4.1\%) wound infection (2004-2007) parallel the previously reported data from Smith et al. ${ }^{34}$ and are slightly lower than infection rates from a study of patients with only cerebral palsy. ${ }^{18}$

The novelty of this study lies in the more recent time interval (2012-2015) and its comparison with the data above.
From 2012 to 2015, data from the SRS database showed an infection rate of $3.2 \% \pm 0.3 \%$. These values, along with superficial $(0.55 \%-1.0 \%)$ and deep $(2.0 \%-2.7 \%)$ infection rates, are significantly lower than those reported in 20042007. Limited evidence exists to validate these trends, but they are very promising. An explanation for these results may be found in the continuous body of research aimed at prevention of complications and infection. Extensive research has been conducted to create standardized, evidence-based protocols for all aspects of surgery. ${ }^{35}$ Literature such as that from the North American Spine Society has confronted topics such as patient education, nutritional status, and antibiotic prophylaxis, while other studies are surfacing on interwound antibiotic application, implants, and surgical approach benefits. 1,10,11,24,28,32,34

In 2012, the SRS began recording data regarding antibiotics, wound washout, and microorganisms. From 2012 to 2015 , intravenous and oral antibiotics were used to treat infection for an average of 49 and 97 days, respectively. The remarkably high usage of antibiotics communicates the need for other forms of infection management. Washout and debridement are the definitive treatment for SSIs,

TABLE 2. Complication and infection rates (2004-2015)

\begin{tabular}{|c|c|c|c|c|c|c|c|c|c|c|c|c|}
\hline Variable & 2004 & 2005 & 2006 & 2007 & 2008 & 2009 & 2010 & 2011 & 2012 & 2013 & 2014 & 2015 \\
\hline Complication rate* & 15 & 16 & 15 & 13 & 11 & 3.4 & 1.1 & 0.9 & 3.5 & 4.2 & 4.2 & 4.4 \\
\hline Wound infection rate* & 6.0 & 5.9 & 5.8 & 5.3 & 5.3 & - & - & - & 2.7 & 3.3 & 3.2 & 3.5 \\
\hline Superficial wound infection* & 1.9 & 1.8 & 1.9 & 1.8 & - & - & - & - & 0.59 & 1.0 & 0.65 & 0.55 \\
\hline Deep wound infection* & 4.1 & 4.1 & 3.9 & 3.5 & - & - & - & - & 2.0 & 2.1 & 2.3 & 2.7 \\
\hline
\end{tabular}

All data given as percentages.

${ }^{*} p<0.05$. 


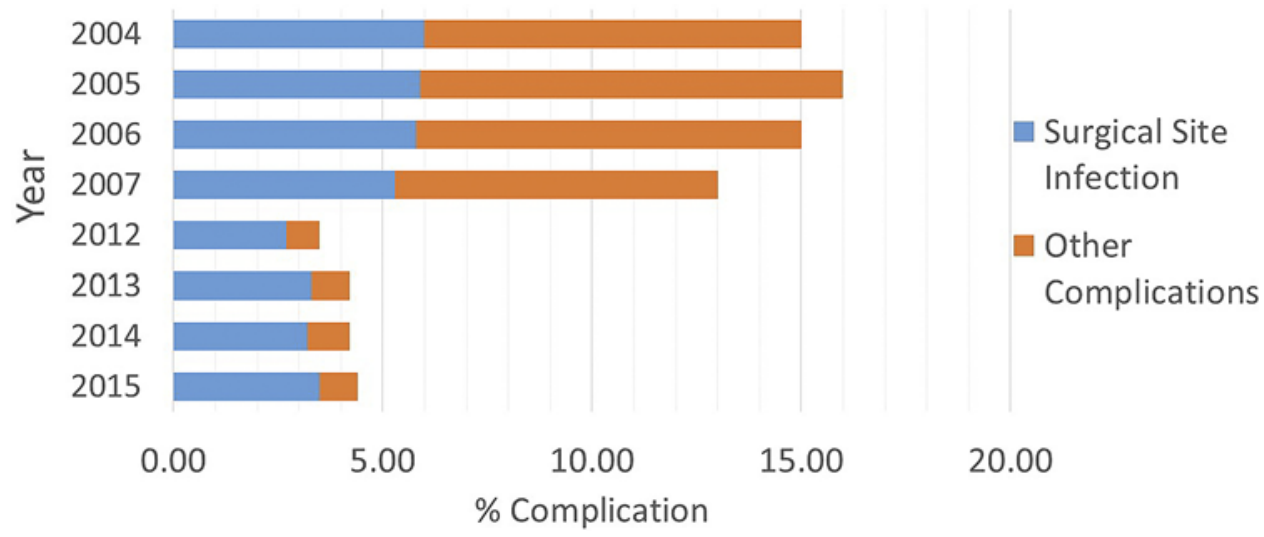

FIG. 2. Graph of the proportion of total complications attributed to SSI.

but no significant changes in use were noted from 2012 to $2015 .{ }^{22}$ The SRS records indicate that $84 \%$ of SSIs used washouts, while $27 \%$ required 3 or more. Other strategies such as dressing changes, wound vacuums, and instrumentation exchange have shown efficacy in eradication of infection but were not investigated in this study. ${ }^{2,17,36}$ In terms of microorganisms, gram positives and gram negatives were implicated equally in cultured infections. MSSA (34.7\%), E. coli (17.7\%), and Pseudomonas (12.5\%) were the 3 most common bacteria detected. Of note, MRSA was present $10.5 \%$ of the time. There is great variation in the literature about bacterial speciation, but these are the main organisms consistently reported. ${ }^{24,36,41}$ Continued insight into their prevalence can guide management principals.

Multiple non-infection-related categories of complications were altered or removed with the updates to the database in 2009. This created challenges while investigating trends, but the data still contained areas of interest that provided prognostic information. VTE (pulmonary embolism [PE] and deep venous thrombosis [DVT]) and sepsis were exceedingly rare occurrences, with no change in incidence from 2004 to 2015. However, respiratory complications (other than PE) decreased significantly. Respiratory complications are often cited as the most common complication following spine surgery in patients with neuromuscular scoliosis. ${ }^{23,25}$ These patients are predisposed to restrictive lung function because of their severe spinal curvature ${ }^{16}$ while other forms of disease impairment pre- dispose to aspiration and pneumonia. Protocols to combat these risk factors have been studied and are likely reasons for the decrease in associated complications. Literature has shown that the use of nocturnal and postoperative positivepressure ventilation, early ambulation, and preoperative optimization may be preventative., ${ }^{75}$

Interestingly, as noted in Table 1, implant usage in complication cases increased significantly during the study period, to approximately $90 \%$ over the final 4 years of this study. However, implant-associated complications decreased by $1.5 \%$ over the same time. There are no largescale studies to examine the mechanisms behind this phenomenon, but some working hypotheses may attribute it partly to the use of vancomycin powder, difference in technique, and titanium/cobalt chrome implants. ${ }^{1,10,11,24,32}$ These variations likely prevent the growth of interwound bacteria and decrease mechanical implant failure.

The relative abundance of spine surgery has welcomed changes to the approaches and equipment used in the operating room. Spinal fusion was used in approximately $80 \%$ of the complications in this study with no change over time. When fusion is broken down by its different approaches, trends begin to appear. The posterior-only approach is the most commonly used and showed increasing prevalence throughout the study period. Interbody approaches are newer and less commonly used, but they also showed significant increases. Anterior-only and posterolateral approaches were significantly less common over the same

TABLE 3. Other complications (2004-2015)

\begin{tabular}{|c|c|c|c|c|c|c|c|c|c|c|c|c|}
\hline Variable & 2004 & 2005 & 2006 & 2007 & 2008 & 2009 & 2010 & 2011 & 2012 & 2013 & 2014 & 2015 \\
\hline Death rate & $0.32(3)$ & $0.7(7)$ & $0.4(4)$ & $2(2)$ & $0.3(1)$ & $0.26(7)$ & $0.16(5)$ & $0.13(5)$ & $0.22(8)$ & $0.03(1)$ & $0.20(7)$ & $0.34(13)$ \\
\hline VTE (PE \& DVT) & $0(0)$ & $0.10(1)$ & $0.10(1)$ & $0(0)$ & $0.31(1)$ & $0(0)$ & $0.028(1)$ & $0.028(1)$ & $0.028(1)$ & $0(0)$ & $0(0)$ & $0(0)$ \\
\hline Other pulmonary* & $2.6(25)$ & $2.4(24)$ & $1.6(16)$ & $1.4(14)$ & $1.2(4)$ & $0.11(3)$ & $0(0)$ & $0(0)$ & $0.11(4)$ & $0(0)$ & $0.05(2)$ & $0.08(3)$ \\
\hline Implant related ${ }^{*}$ & $1.9(18)$ & $1.9(19)$ & $1.9(19)$ & $2.1(21)$ & $0.3(1)$ & $0.71(19)$ & $0.25(8)$ & $0.21(8)$ & $0.25(9)$ & $0.58(22)$ & $0.33(12)$ & $0.34(13)$ \\
\hline Neurological deficit & $0.63(6)$ & $0.7(7)$ & $0.7(7)$ & $0.90(9)$ & $0(0)$ & $0.48(13)$ & $0.57(18)$ & $0.48(18)$ & $0.45(16)$ & $0.68(26)$ & $0.71(26)$ & $0.52(20)$ \\
\hline Sepsis & $0(0)$ & $0.10(1)$ & $0(0)$ & $0.20(2)$ & $0(0)$ & $0(0)$ & $0.028(1)$ & $0.028(1)$ & $0(0)$ & $0(0)$ & $0(0)$ & $0.026(1)$ \\
\hline Hematoma & $1.8(17)$ & $1.4(14)$ & $1.4(14)$ & $0.5(5)$ & $0.3(1)$ & - & - & - & - & - & - & - \\
\hline Dural tear & $1.1(10)$ & $0.4(4)$ & $1.0(10)$ & $0.80(8)$ & $1.2(4)$ & - & - & - & - & - & - & - \\
\hline
\end{tabular}

All data given as percentage (number of patients).

${ }^{*} p<0.001$. 
time period. These trends are likely a result of new techniques and innovation impacting the greater body of spine surgery preferences. There are considerable data on the risks and benefits of certain approaches, particularly anterior, which has previously shown higher complication rates. ${ }^{13}$

Other surgical techniques also showed changes throughout the study. Although the use of osteotomy and implants has previously been associated with higher complication rates, both increased from 2004 to 2015 even though complications decreased. Surgeon preference and degree of pathology play a role in those data, but further discussion of the reason for their increases is beyond the scope of this report.

Lastly, IONM usage was unchanged throughout the 12year study. Rumalla et al. ${ }^{29}$ had previously shown increasing utilization from 2007 to 2011; however, their data were based on ICD-9-CM coding for IONM. ICD coding for IONM was not created until 2007 and thus may have involved a lag time for reliability.

The present study is not without limitations. Although the database contains prospective data, the analysis was performed retrospectively. The data are also self-reported. The nature of complication data lends itself to reporting biases. Obviously, participating physicians may underreport their surgical complications, but there are many reasons for underreporting of medical complications. The simplest explanation is the variance on what constitutes a complication. Surgeons may not be as immediately focused on medical complications. Yearly reporting of cases to the SRS database and overall latency of some medical complications could contribute to shorter follow-up times and decreased complication rates. As previously mentioned, there were substantial changes to the SRS database during the study period. In 2008, the database was shut down temporarily for reorganization. In 2009, an updated questionnaire was created, contributing to less-robust data sets from 2009 to 2011. This created a challenge during interpretation of results as new categories of data were added, while others were changed or discontinued. Changes in reporting and required fields may also account for a large component of the reduction in miscellaneous complications observed between the 2 chronological cohorts.

Although this study presents promising results in terms of decreased complication and infection rates, results need to be tempered against the limitations discussed above. The trend of improvement is encouraging as we strive to further reduce complications and optimize outcomes in this challenging patient population.

\section{References}

1. Borkhuu B, Borowski A, Shah SA, Littleton AG, Dabney KW, Miller F: Antibiotic-loaded allograft decreases the rate of acute deep wound infection after spinal fusion in cerebral palsy. Spine (Phila Pa 1976) 33:2300-2304, 2008

2. Canavese F, Krajbich JI: Use of vacuum assisted closure in instrumented spinal deformities for children with postoperative deep infections. Indian J Orthop 44:177-183, 2010

3. Coe JD, Smith JS, Berven S, Arlet V, Donaldson W, Hanson D, et al: Complications of spinal fusion for Scheuermann kyphosis: a report of the Scoliosis Research Society Morbidity and Mortality Committee. Spine (Phila Pa 1976) 35:99-103, 2010
4. Deyo RA, Gray DT, Kreuter W, Mirza S, Martin BI: United States trends in lumbar fusion surgery for degenerative conditions. Spine (Phila Pa 1976) 30:1441-1447, 2005

5. Deyo RA, Mirza SK: Trends and variations in the use of spine surgery. Clin Orthop Relat Res 443:139-146, 2006

6. Deyo RA, Mirza SK, Martin BI, Kreuter W, Goodman DC, Jarvik JG: Trends, major medical complications, and charges associated with surgery for lumbar spinal stenosis in older adults. JAMA 303:1259-1265, 2010

7. Eagle M, Bourke J, Bullock R, Gibson M, Mehta J, Giddings $\mathrm{D}$, et al: Managing Duchenne muscular dystrophy-the additive effect of spinal surgery and home nocturnal ventilation in improving survival. Neuromuscul Disord 17:470-475, 2007

8. Fang A, Hu SS, Endres N, Bradford DS: Risk factors for infection after spinal surgery. Spine (Phila Pa 1976) 30:14601465,2005

9. Fuller JE: Morbidity and Mortality Committee. SRS News. (http://www.srs.org/enews/2015/09/articles.php?content=11) [Accessed August 10, 2017]

10. Gans I, Dormans JP, Spiegel DA, Flynn JM, Sankar WN, Campbell RM, et al: Adjunctive vancomycin powder in pediatric spine surgery is safe. Spine (Phila Pa 1976) 38:17031707, 2013

11. Godil SS, Parker SL, O’Neill KR, Devin CJ, McGirt MJ: Comparative effectiveness and cost-benefit analysis of local application of vancomycin powder in posterior spinal fusion for spine trauma: clinical article. J Neurosurg Spine 19:331335,2013

12. Hamilton DK, Smith JS, Sansur CA, Glassman SD, Ames CP, Berven SH, et al: Rates of new neurological deficit associated with spine surgery based on 108,419 procedures: a report of the Scoliosis Research Society Morbidity and Mortality Committee. Spine (Phila Pa 1976) 36:1218-1228, 2011

13. Huang KT, Hazzard M, Thomas S, Chagoya G, Berg RW, Adogwa O, et al: Differences in the outcomes of anterior versus posterior interbody fusion surgery of the lumbar spine: a propensity score-controlled cohort analysis of 10,941 patients. J Clin Neurosci 22:848-853, 2015

14. Jackson KL II, Devine JG: The effects of obesity on spine surgery: a systematic review of the literature. Global Spine J 6:394-400, 2016

15. Khirani S, Bersanini C, Aubertin G, Bachy M, Vialle R, Fauroux B: Non-invasive positive pressure ventilation to facilitate the post-operative respiratory outcome of spine surgery in neuromuscular children. Eur Spine J 23 (Suppl 4):S406S411, 2014

16. Kurz LT, Mubarak SJ, Schultz P, Park SM, Leach J: Correlation of scoliosis and pulmonary function in Duchenne muscular dystrophy. J Pediatr Orthop 3:347-353, 1983

17. Levi AD, Dickman CA, Sonntag VK: Management of postoperative infections after spinal instrumentation. J Neurosurg 86:975-980, 1997

18. Lipton GE, Miller F, Dabney KW, Altiok H, Bachrach SJ: Factors predicting postoperative complications following spinal fusions in children with cerebral palsy. J Spinal Disord 12:197-205, 1999

19. Lurie JD, Birkmeyer NJ, Weinstein JN: Rates of advanced spinal imaging and spine surgery. Spine (Phila Pa 1976) 28:616-620, 2003

20. MacEwen GD, Bunnell WP, Sriram K: Acute neurological complications in the treatment of scoliosis. A report of the Scoliosis Research Society. J Bone Joint Surg Am 57:404408, 1975

21. Martin CT, Pugely AJ, Gao Y, Skovrlj B, Lee NJ, Cho SK, et al: Reliability of a surgeon-reported morbidity and mortality database: a comparison of short-term morbidity between the Scoliosis Research Society and National Surgical Quality Improvement Program databases. Iowa Orthop J 36:147154, 2016 
22. Massie JB, Heller JG, Abitbol JJ, McPherson D, Garfin SR: Postoperative posterior spinal wound infections. Clin Orthop Relat Res (284):99-108, 1992

23. Mohamad F, Parent S, Pawelek J, Marks M, Bastrom T, Faro F, et al: Perioperative complications after surgical correction in neuromuscular scoliosis. J Pediatr Orthop 27:392-397, 2007

24. Molinari RW, Khera OA, Molinari WJ III: Prophylactic intraoperative powdered vancomycin and postoperative deep spinal wound infection: 1,512 consecutive surgical cases over a 6-year period. Eur Spine J 21 (Suppl 4):S476-S482, 2012

25. Parchi PD, Evangelisti G, Andreani L, Girardi F, Darren L, Sama A, et al: Postoperative spine infections. Orthop Rev (Pavia) 7:5900, 2015

26. Parent S, Barchi S, LeBreton M, Casha S, Fehlings MG: The impact of specialized centers of care for spinal cord injury on length of stay, complications, and mortality: a systematic review of the literature. J Neurotrauma 28:1363-1370, 2011

27. Rajaee SS, Bae HW, Kanim LE, Delamarter RB: Spinal fusion in the United States: analysis of trends from 1998 to 2008. Spine (Phila Pa 1976) 37:67-76, 2012

28. Rechtine GR, Bono PL, Cahill D, Bolesta MJ, Chrin AM: Postoperative wound infection after instrumentation of thoracic and lumbar fractures. J Orthop Trauma 15:566-569, 2001

29. Rumalla K, Yarbrough CK, Pugely AJ, Koester L, Dorward IG: Spinal fusion for pediatric neuromuscular scoliosis: national trends, complications, and in-hospital outcomes. J Neurosurg Spine 25:500-508, 2016

30. Schuster JM, Rechtine G, Norvell DC, Dettori JR: The influence of perioperative risk factors and therapeutic interventions on infection rates after spine surgery: a systematic review. Spine (Phila Pa 1976) 35 (9 Suppl):S125-S137, 2010

31. Sharma S, Wu C, Andersen T, Wang Y, Hansen ES, Bünger CE: Prevalence of complications in neuromuscular scoliosis surgery: a literature meta-analysis from the past 15 years. Eur Spine J 22:1230-1249, 2013

32. Slosar PJ Jr: Technological advancements in spinal fusion implants: a summary of the current scientific and clinical research on titanium engineered surfaces. J Spinal Res Found 9:35-41, 2014

33. Smith JS, Fu KM, Polly DW Jr, Sansur CA, Berven SH, Broadstone PA, et al: Complication rates of three common spine procedures and rates of thromboembolism following spine surgery based on 108,419 procedures: a report from the Scoliosis Research Society Morbidity and Mortality Committee. Spine (Phila Pa 1976) 35:2140-2149, 2010

34. Smith JS, Shaffrey CI, Sansur CA, Berven SH, Fu KM, Broadstone PA, et al: Rates of infection after spine surgery based on 108,419 procedures: a report from the Scoliosis Research Society Morbidity and Mortality Committee. Spine (Phila Pa 1976) 36:556-563, 2011

35. Sponseller PD, LaPorte DM, Hungerford MW, Eck K, Bridwell KH, Lenke LG: Deep wound infections after neuromuscular scoliosis surgery: a multicenter study of risk factors and treatment outcomes. Spine (Phila Pa 1976) 25:24612466, 2000

36. Vitale MG, Riedel MD, Glotzbecker MP, Matsumoto H, Roye DP, Akbarnia BA, et al: Building consensus: development of a best practice guideline (BPG) for surgical site infection (SSI) prevention in high-risk pediatric spine surgery. J Pediatr Orthop 33:471-478, 2013

37. Walid MS, Robinson JS Jr: Economic impact of comorbidities in spine surgery. J Neurosurg Spine 14:318-321, 2011

38. Wang MC, Kreuter W, Wolfla CE, Maiman DJ, Deyo RA: Trends and variations in cervical spine surgery in the United States: Medicare beneficiaries, 1992 to 2005. Spine (Phila Pa 1976) 34:955-963, 2009

39. Webb ML, Lukasiewicz AM, Samuel AM, Bohl DD, Basques BA, Varthi AG, et al: Overall similar infection rates reported in the physician-reported Scoliosis Research Society database and the chart-abstracted American College of Surgeons National Surgical Quality Improvement Program database. Spine (Phila Pa 1976) 40:1431-1435, 2015

40. Weinstein JN, Lurie JD, Olson PR, Bronner KK, Fisher ES: United States' trends and regional variations in lumbar spine surgery: 1992-2003. Spine (Phila Pa 1976) 31:2707-2714, 2006

41. Weinstein MA, McCabe JP, Cammisa FP Jr: Postoperative spinal wound infection: a review of 2,391 consecutive index procedures. J Spinal Disord 13:422-426, 2000

42. Whitehouse JD, Friedman ND, Kirkland KB, Richardson WJ, Sexton DJ: The impact of surgical-site infections following orthopedic surgery at a community hospital and a university hospital: adverse quality of life, excess length of stay, and extra cost. Infect Control Hosp Epidemiol 23:183-189, 2002

\section{Disclosures}

Dr. Samdani reports being a consultant for DePuy Synthes Spine, Ethicon, Globus Medical, Misonix, Stryker, and Zimmer Biomet; and being a board member or receiving a committee appointment for the Setting Scoliosis Straight Foundation, Scoliosis Research Society, and Children's Spine Study Group. Dr. Pahys reports being a consultant for DePuy Synthes Spine, Globus Medical, and Zimmer Biomet. Dr. Hanson has received royalties, acted as a consultant, served on the speakers bureau, and is a patent holder for DePuy Synthes Spine; and served on the speakers bureau for NuVasive. Dr. Hwang has served on the speakers bureau for Zimmer Biomet.

\section{Author Contributions}

Conception and design: Hwang. Acquisition of data: Hwang, Blanke. Analysis and interpretation of data: Hwang, Cognetti, Keeny. Drafting the article: Hwang, Cognetti, Keeny. Critically revising the article: all authors. Reviewed submitted version of manuscript: all authors. Approved the final version of the manuscript on behalf of all authors: Hwang. Statistical analysis: Hwang, Cognetti, Keeny. Study supervision: Hwang.

\section{Correspondence}

Steven Hwang, Shriners Hospitals for Children-Philadelphia, 3551 N Broad St., Philadelphia, PA 19140. email: sthwang@ shrinenet.org. 